\title{
Development of IoT based Security System for Fire Monitoring and Prevention in Tanzanian Industries
}

\author{
Jesus de la Paix Irakomeye ${ }^{1}$, Abel Nshimiye ${ }^{1}$, Kisakyake Ng'ondya ${ }^{1}$, Elibariki J. Sumari ${ }^{1}$, \\ Dr. Judith Leo ${ }^{2}$ and Dr. Anael Sam ${ }^{2}$ \\ Scholars ${ }^{1}$, Lecturer ${ }^{2}$, Senior Lecturer ${ }^{2}$ \\ School of Computational and Communication Sciences and Engineering \\ Nelson Mandela African Institution of Science and technology
}

Arusha-Tanzania

\begin{abstract}
Over the past years, there have been great advances in ICTs which have led to the development of fire monitoring and prevention systems. Despite the existence of these solutions, fire incidents especially in Tanzanian have been a major problem in industries which leads to the destruction of materials and loss of lives. With the help of wireless sensor networks (WSN) and the internet of things (IoT), the monitoring and prevention of fire outbreaks become easy and reliable. The present work explores the existing fire monitoring and prevention systems and then, designs and develops an innovative security system for early fire monitoring and prevention in Tanzanian industries through the use of emerging technologies such as WSN and IoT. The results of the system evaluation shows that $88 \%$ of users were satisfied with its functionalities. This is because the system works in real-time and through the use of different sensors such as DHT sensor, MQ2 sensor, and Flame sensor to monitor humidity, temperature, smoke, flammable gasses, and fire outbreak in the different work areas. The use of the mobile application and cloud subsystem, the developed system can timely alert the users via their mobile phones on the status of the fire and different parameters.
\end{abstract}

Key Words: Wireless Sensor Network, Internet of Things, Fire monitoring, Fire prevention.

\section{INTRODUCTION}

The industry fire hazard outbreak continues to devastate industries repeatedly in different parts of the world including Tanzania. The industrial fire puts an end to the dreams and efforts of traders to overcome the vicious cycle of poverty. Due to this situation, most existing industries have used fire-fighting and monitoring precautions and mechanisms so as eradicate the resulting huge destruction of properties, goods, and loss of their capital for business during fire hazard outbreaks [1].

According to the literature, there have been great advances in ICTs which have led to the development of effective fire monitoring and prevention systems. Despite the existence of these solutions, fire incidents especially in Tanzanian industries are still a major challenge. These challenges include small surveillance capacity, a simple human-computer interface system, poor reliability in detection, slow response time, and a non-flexible network interface system. In addition, most of the existing traditional fire monitoring systems have a high rate of fake negative reactions and false-positive reactions leading to the time delay in fire detection and prevention [2]. As a result, currently, most of the industries especially in Tanzania are exploring and searching for an appropriate secured system for timely fire monitoring and prevention technologies.

Fortunately, the advancement in ICT technologies and their application through the use of the internet of things (IoT) and wireless sensor networks (WSN) have shown great successes in solving existing challenges in different sectors. Researchers believe that if these technologies can be innovatively applied can assist in fire management activities. In brief, fire management can be analyzed in three phases within the infrastructure of the industry as identified by [3]. The first phase focuses on fire avoidance, the second phase deals with a decision support system in firefighting and the third phase focuses on plans for the best recovery strategy after the fire incidence. Hence, as it has been noted in the literature that when IoTs are integrated with WSN; 
they create a high level of intelligence for keeping up many product categories, amounts, complex fire threat components, and huge scope of supplies for fire checking and battling. Hence, they can be further explored toward solving the existing fire challenges in Tanzania. In addition, IoT has high versatility and high asset sharing abilities for handling different complex business information and if integrated innovatively with the WSN can play a significant part in the fire alarm, fire control facility monitoring, fire equipment management, fire early warning, prevention, and early disposal [4]. Therefore, this study is going to take the advantage of IoT and WSN to design and develop an IoT-based security system for early fire monitoring and prevention in Tanzanian industries. The rest of this paper includes Section 2 which discusses briefly related works, then, Section 3 which presents materials and methodology, Section 4 which presents the results, and lastly, Section 5 which concludes with a brief discussion.

\section{RELATED WORKS}

According to the literature, there are several research that have been conducted about fire detection and monitoring; for example, the study done by [1] whereby they have applied WSN and IoT to create subsystems that use multiple sensors for detecting fire outbreaks. They used the data processing subsystem to collect data from the sensing subsystem through Xbee, and lastly, analysed and uploaded the data to the cloud. This system was found effective but it has the challenge of untimely detection and reporting of the incidences. The other study was done by [5] and [6] to integrate WSN and IoT-based platform to detect fire outbreak at early stage. These systems lacked prevention mechanisms. Also, the research done by [7] described the design of a home fire alarm with an Arduino board-based system through a GSM module. The project purposely was for safety where the main point is to avoid fire accidents to the residents and properties inside the home. The other study was done by [8] to describe only the application of WSN and IoTs to provides real-time monitoring of fire outbreaks in markets. The systems integrated tree subsystems namely, the sensing subsystem which uses multiple sensors for detecting fire outbreaks. Lastly, the other study was done by [9] to design and develop a simple hardware circuit that enables every user to use the fire sensor, temperature sensor, gas sensor, smoke sensor at home and in industries.

Based on the reviewed study, it was observed that there is a need to explore further how to innovatively integrate WSN and IoTs towards obtaining timely and secured fire monitoring and prevention system for Tanzanian industries as the challenge still exist and with the same causes of fire parameters, condition, and environment to mention a few.

\section{MATERIALS AND METHODOLOGY}

\subsection{System Design}

This work used agile software development methodology (ASDM) from the stage of problem identification, solution design, develop and evaluation. The ASDM was chosen for the development of the IoT-based security system for early fire monitoring and prevention because it adapts easily and quickly to change, has better visibility to project control and performance; and also, allows continuous improvement at each stage of the system[10]. Figure 1 is the architecture of the proposed system whose design consider the major challenge in fire monitoring and prevention. The design has four units which are sensing and monitoring, data processing, mobile application, and fire extinguisher units. Whole units of the system provide real-time monitoring, detection, and prevention. 


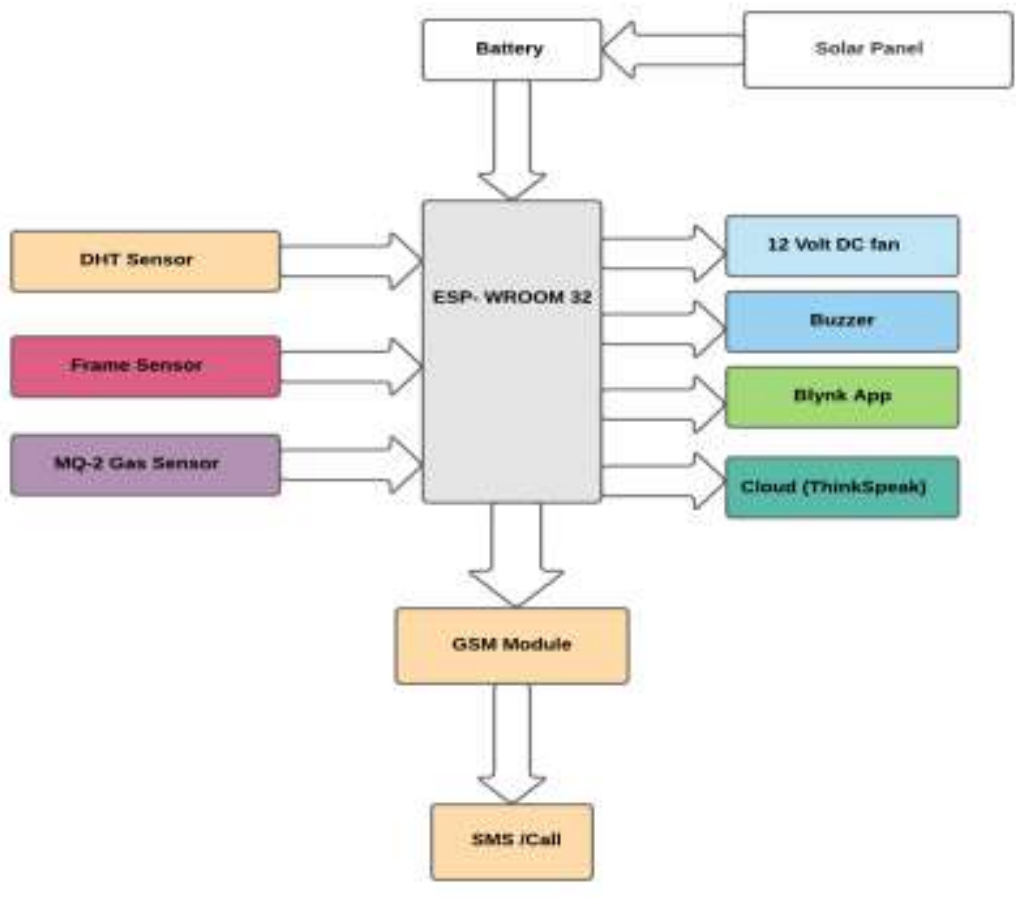

Figure 1: System Architecture

The following is a brief explanation of the four units that have been considered in the design of the IoT based security system for early fire monitoring and prevention;

\subsubsection{Sensing and Monitoring Unit}

The sensing and monitoring unit is composed of different sensors that perform sensing and monitoring of the industrial parameters that cause fire outbreaks. These parameters include leakage smells of welding, sawing, burnt wires, and machine which operate extensively; and also, gases, liquid, temperature, humidity, smoke, and carbon monoxide which may lead to the occurrence of fire. The sensing and monitoring unit has the following sensors to sense all the mentioned parameters; a smoke and carbon monoxide sensor (MQ-02), a temperature sensor (DHT22), and a fire flame sensor to capture fire characteristics [1][11]. These sensors send data to the ESP32 board and then, the ESP32 transmits them to the data processing operation through a wireless network [12].

\subsubsection{Data Processing Unit}

The major purpose of the IoT-based security system for early fire monitoring and prevention is to process all data received from the sensing operation in real-time. The other functionalities of the data processing unit include; visualization and analysis of received data from sensors, the process of sending data from sensors to the cloud for the mobile application to perform visualization and communication activities, triggering an alarm if there is smoke, gas, and fire outbreak. When there is smoke and gas during the fire outbreak, the data processing unit uses the GSM module to call and send SMS; and if there is a risk of a fire outbreak, the system identifies the exact location within the industry and then, trigger an alarm real-time based.

\subsubsection{Mobile Application Unit}

The mobile application unit performs visualization and real-time monitoring of the fire outbreak parameters. The following are the features of the mobile application which include; visualization of data from each sensor in the industry, reporting of any faulty of each sensor, and providing notification (alarm) in the event of a fire outbreak to the administrator or the people in charge.

\subsubsection{Fire Extinguisher Unit}

The operation of the fire extinguisher unit is done when there is a fire outbreak in the industry. It is integrated with the system as a solution to try to hold the fire. When the fire has occurred it will be activated at the same time as the alarm and a notification SMS or call will be sent to the mobile to indicate that there is a fire in the industry. In addition, the fire extinguisher unit is integrated with the fire ventilation sub-unit to assist during the fire outbreak incidence by switching the fan on or off when required. 


\section{RESULTS AND DISCUSSION}

The section presents briefly the results and its discussion of the developed IoT-based security system for early fire monitoring and prevention per the classified system units.

\subsection{Results}

\subsubsection{Sensing and Monitoring Unit}

The sensing operation was properly interfaced, and it was able to function and produce the desired outcomes as shown in Figure 2. The temperature, carbon monoxide, smoke, and fire flame were all detected and also, these fire parameters were successfully transmitted to the data processing unit through the use of sending operation which is interfaced with the WiFi module [13] [14].

\subsubsection{Data Processing Unit}

The data processing unit was able to receive data through a WiFi module. Then, two tasks were performed which are to receive compete for data and analyze the received data against normal specified levels or rates of the collected parameters in the industry. If the values of the parameters exceed the required level then the system triggers an alarm and sends a notification message through the GSM module to the responsible people. In addition, the data sending unit uploads all data to the cloud (Think Speak) [15][3] then the data from the sensors are visualized in the Think Speak as shown in Figure 2.
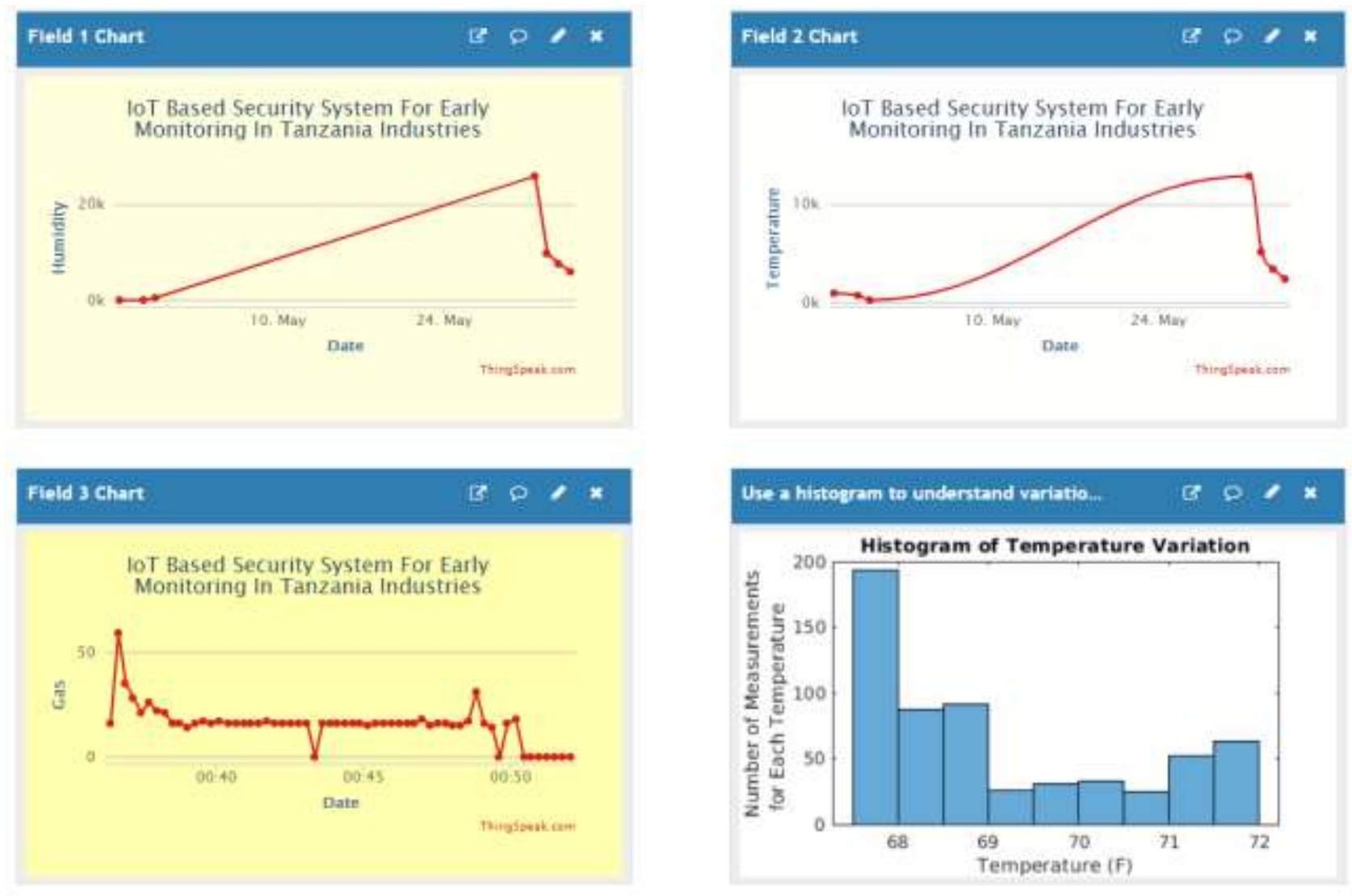

Figure 2: Data Visualization

\subsubsection{Mobile Application Unit}

The mobile application receives data from sensors through a Wi-Fi module and then, visualizes the data via mobile application. In case, the values of the sensed and visualized parameters exceed the normal level; the mobile application triggers the alarm and send a warning notification of fire outbreak to the responsible people. In addition, the mobile application sends a notification if there is a default in the sensors. The visualization of the data through the use of the mobile application is shown in Figure 3 , Figure 4, and Figure 5 [16][13]. 
International Journal of Advances in Scientific Research and Engineering (ijasre), Vol 7 (12), December -2021

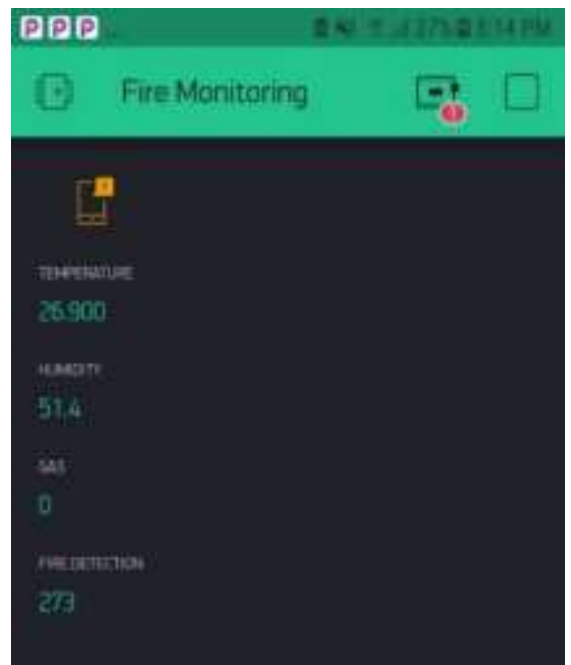

Figure 3 Fire detected

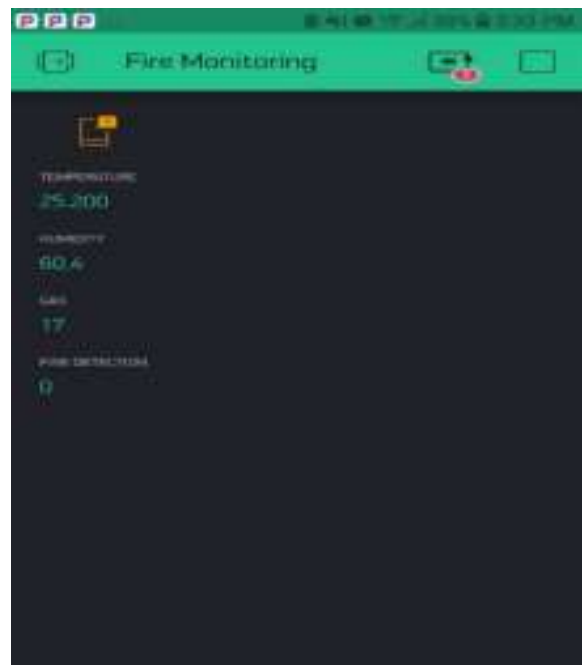

Figure 4 Gas detected

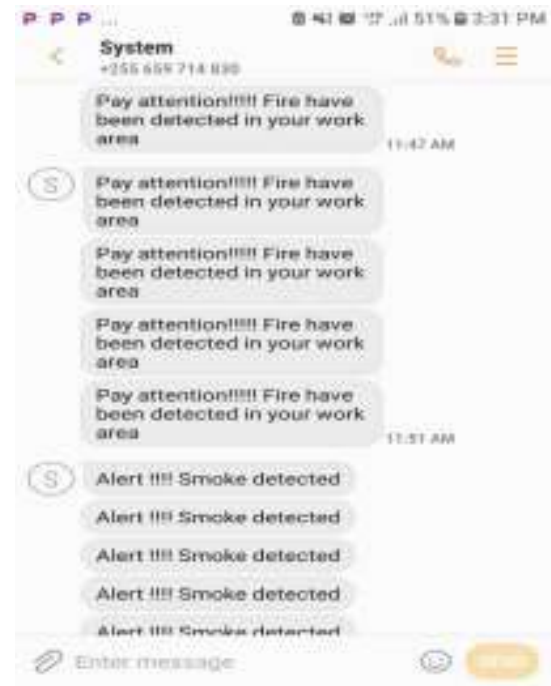

Figure 5 fire and smoke detected

\subsubsection{Fire Extinguisher Unit}

The fire extinguisher unit was able to function and produce the desired outcomes whereby it is activated when the fire has occurred. The fire extinguisher unit in return activates the fan ventilation sub-unit in order to hold spread off the smoke out of the industry as shown in Figure 6.

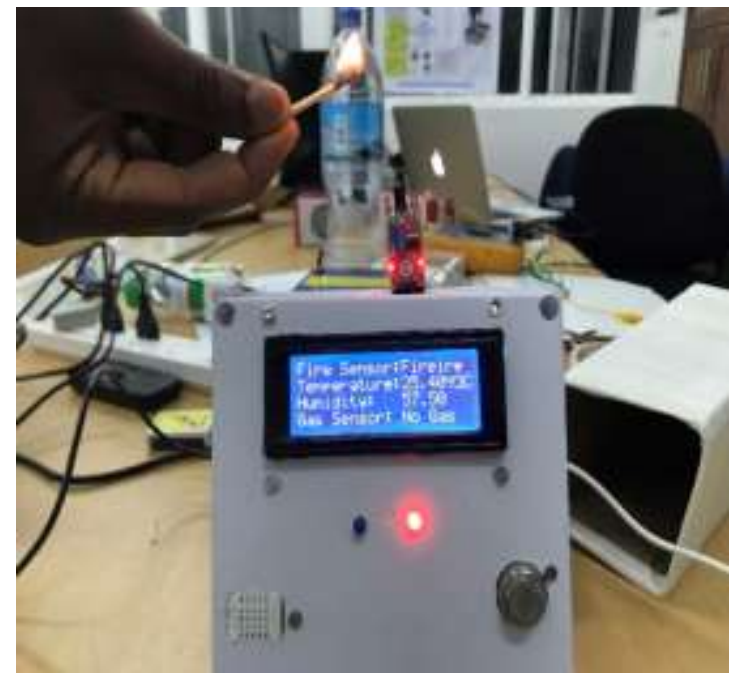

Figure 6: Fire Detection

\subsubsection{System Evaluation}

In the system evaluation stage, a field study was conducted using the developed prototype. The field study consisted of 50 participants; were by 15 of them worked in the fire department, 20 of them worked in industries, 10 of them were ICT experts who have experience working with ICT based fire management systems and the remaining 5 of them were people who have experienced a fire outbreak in industries. The study was conducted in the Arusha region in Tanzania, whereby the male to female ratio of participants was 70:30 respectively. According to the questionnaire used in the evaluation process, the discussion was based on evaluating the system's performance, time-effectiveness, security, user friendly, suitability in developing countries, and its quality to mention a few. The results of the system evaluation showed that $88 \%$ of users were satisfied with its functionalities. The remaining $12 \%$ represents participants who were not sure if ICT can timely monitor and prevent fire outbreaks due to the fact that the system to some extent depends on human interference. 


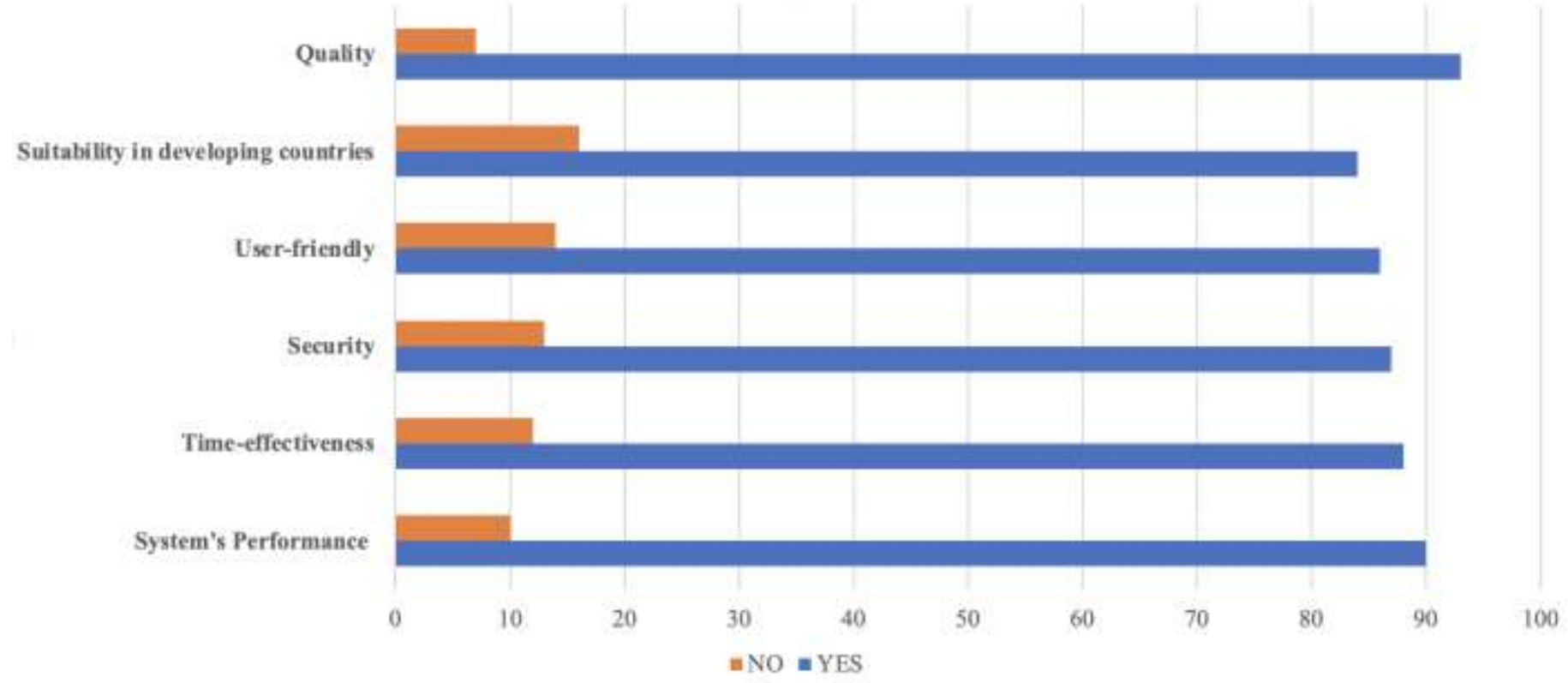

Figure 7: System Evaluation Results

\section{CONCLUSION}

The industry outbreak cause damage to not only buildings and goods available in the industry but also destroys people's life and health. According to recent studies, it has been noted that most of these fire outbreaks are caused by the same causes, parameters, and conditions in these industries. Therefore, it is high time to take advantage of emerging technologies and innovation, whereby in this study IoTs have been integrated innovatively with WSN to develop IoT based security system for early fire monitoring and prevention. The developed system has taken consideration to work effectively in industries that are in developing countries; especially in Tanzania. According to the system's results and its validation, the developed system has proved to work effectively in Tanzanian industries. The study recommends further research to be done in the same area to explore other emerging technologies such as machine learning (ML) and artificial intelligence (AI) on how they can innovatively be integrated with IoTs and WSN to add value in the development of the secured system for fire monitoring and prevention in Tanzania and other countries at large.

\section{REFERENCES}

[1] R. Hilary, P. Rotich, A. Geofrey, and A. Sam, "Early Fire Detection System in Tanzania Markets †," 2020, doi: 10.3390/ecsa-7-08215.

[2] H. M. Fadhil, A. Kadhum, and R. Abdulkadhum, "Multi-effectiveness Smart Home Monitoring System Based Artificial Intelligence through Arduino,” J. Softw., vol. 12, no. 7, pp. 546-558, 2017, doi: 10.17706/jsw.12.7.546-558.

[3] L. Bodrožić, D. Stipaničev, and M. Štula, “Agent based data collecting in a forest fire monitoring system,” SoftCOM 2006 - Int. Conf. Software, Telecommun. andComputer Networks, pp. 326-330, 2006, doi: 10.1109/SOFTCOM.2006.329772.

[4] S. R. Vijayalakshmi and S. Muruganand, "Internet of Things technology for fire monitoring system," Int. Res. J. Eng. Technol., vol. 4, no. 6, pp. 2140-2147, 2017.

[5] R. P. Deekshath Dharanya, K. R. Dimpil Kabadia G Deepak Dinakaran, and S. Shanthini Assistant Professor, "IoT Based Environmental Monitoring System using Arduino UNO and Thingspeak," IJSTE-International J. Sci. Technol. Eng. |, vol. 4, no. 9, pp. 68-75, 2018.

[6] A. Sharma, P. K. Singh, and Y. Kumar, "An integrated fire detection system using IoT and image processing technique for smart cities,” Sustain. Cities Soc., vol. 61, p. 102332, 2020, doi: 10.1016/j.scs.2020.102332. 
[7] N. N. Mahzan, N. I. M. Enzai, N. M. Zin, and K. S. S. K. M. Noh, "Design of an Arduino-based home fire alarm system with GSM module,” J. Phys. Conf. Ser., vol. 1019, no. 1, 2018, doi: 10.1088/1742-6596/1019/1/012079.

[8] K. Kumar, N. Sen, S. Azid, and U. Mehta, “A Fuzzy Decision in Smart Fire and Home Security System,” Procedia Comput. Sci., vol. 105, no. December 2016, pp. 93-98, 2017, doi: 10.1016/j.procs.2017.01.207.

[9] P. Dhruvajyoti and J. Debashis, “GSM Based Fire Sensor Alarm Using Arduino,” Int. J. Sci. Eng. Res., vol. 7, no. 4, pp. 259-262, 2016.

[10] S. Al-Saqqa, S. Sawalha, and H. Abdelnabi, “Agile software development: Methodologies and trends," Int. J. Interact. Mob. Technol., vol. 14, no. 11, pp. 246-270, 2020, doi: 10.3991/ijim.v14i11.13269.

[11] B. Sarwar, I. S. Bajwa, N. Jamil, S. Ramzan, and N. Sarwar, “An intelligent fire warning application using IoT and an adaptive neuro-fuzzy inference system,” Sensors (Switzerland), vol. 19, no. 14, 2019, doi: 10.3390/s19143150.

[12] B. Amutha, C. Rajeshbabu, C. H. Neehar, and E. Sumanth, "Gas and smoke detection in industries using nodemcu," J. Crit. Rev., vol. 7, no. 8, pp. 1504-1507, 2020, doi: 10.31838/jcr.07.08.299.

[13] D. Toradmalle, J. Muthukuru, and B. Sathyanarayana, "Certificateless and provably-secure digital signature scheme based on elliptic curve,” Int. J. Electr. Comput. Eng., vol. 9, no. 4, pp. 3228-3231, 2019, doi: 10.11591/ijece.v9i4.ppxx-xx.

[14] A. Ridoy, M. Nazim, U. Nayim, F. Tafannum, and M. M. Ali, "Design and Implementation of Arduino Based Air Quality Measurement Meter with Digital Dashboard on Smartphone Using Blynk," IJCSN-International J. Comput. Sci. Netw., vol. 8, no. 1, pp. 58-63, 2019.

[15] Y. Li, J. Yi, X. Zhu, Z. Wang, and F. Xu, “Developing A Fire Monitoring and Control System Based on IoT,” vol. 133, pp. 174-178, 2016, doi: 10.2991/aiie-16.2016.40.

[16] Khin Thandar Tun | Aye Sandar Aung | May Lwin Thant, "GSM Based Fire Security System,” Int. J. Trend Sci. Res. Dev. Int. J. Trend Sci. Res. Dev., vol. 3, no. 5, pp. 1686-1690, 2019, doi: https://doi.org/10.31142/ijtsrd26697. 